\title{
Studying the occupied urban land development in Portugal Mainland between 1990-2018
}

\author{
JOSÉ MANUEL NARANJO GÓMEZ \\ Department of Graphical Expression \\ University of Extremadura \\ Adolfo Suárez Avenue, no number, Badajoz, 06007 \\ SPAIN \\ RUI ALEXANDRE CASTANHO \\ Faculty of Applied Sciences, WSB University \\ 41-300 Dabrowa Górnicza \\ POLAND \\ and \\ College of Business and Economics, University of Johannesburg \\ PO Box 524, Auckland Park \\ SOUTH AFRICA \\ JACINTO GARRIDO VELARDE \\ University Research Institute for Sustainable \\ Territorial Development (INTERRA), \\ University of Extremadura, SPAIN \\ and \\ Department of Social Sciences, Languages and Literatures \\ University of Extremadura \\ Elvas Avenue, no number, Badajoz, 06006 \\ SPAIN
}

\begin{abstract}
Land intended for urban use is becoming increasingly concerned in our society, mainly for environmental reasons. In turn, it is an excellent indicator of the economic development of the territory. This study evaluates the urban area's change between 1990 and 2018 in Portugal Mainland and its relationship with the population. To achieve this aim, a Geographic Information System was used, and based on Corine Land Cover (CLC) data, the urban area occupied in 1990 and 2018 was determined. Also, together with the population in 2011, they formed a multi-temporal database. An exploratory analysis was carried out on it. The relationship between the population was analyzed in 2011 and the occupied urban area in 2018. Finally, the statistical inference was used, comparing the occupied urban area's average populations in 1990 and 2018. The results suggest that urban expansion has been very significant and identified the territories with the highest growth.
\end{abstract}

Key-Words: Geographic Information Systems; Land Planning; Land Use Changes; Portugal Mainland; Sustainable Development; Territorial Governance and Management, population, statistical inference.

Received: April 10, 2021. Revised: September 18, 2021. Accepted: September 30, 2021. Published: October 4, 2021.

\section{Introduction}

Land-uses and territorial occupation modifications are a matter of exceptional importance at global, national, and regional levels once they provide results on the biological, natural, and economic structures $[1,2]$.
In this regard, land systems include all methods and activities related to the human use of the territories, including technological and organizational progress and coordination as well as the interests earned from land and the unintended cultural and environmental values of societal activities [3-5]. So, these systems 
have essential links that lead to a variation in the land cover [6-8].

Land-use and regional occupation changes are indispensable symbols of human activities over the autochthonous environment [1]. Whereby, the assessment of land-use changes has continued necessary in various thematic fields as spatial planning; regional and urban planning; territorial management and governance; ecosystems protection and conservation; strategic planning; economic; or financial, and social are just a few examples of those referred inter-connected disciplines [9-13]. Because understanding urban dynamics will provide territory managers with a useful tool to better manage the territory.

Based on the previously mentioned, this study intends to analyze and evaluate the changes and evolution dynamics in the Portugal Mainland land uses between 1990 and 2018, based on the CORINE Land Cover (CLC) data. Nonetheless, the population had to be taken into account. For this reason, it was determined whether between the years analyzed there was a significant change in the evolution of the area analyzed for urban land uses. Besides, what was the population distribution and the influence on these changes in the population and what is more, it was analyzed if the Portuguese government's actions have produced differences in the urban land generation. Therefore, throughout evaluating these evolutionary patterns and dynamics, we present some guidelines and proposals for future territorial planning and management strategies and policies to be produced and administered over this country. In this regard, this type of analysis has been applied over a wide temporal section and analyzing a large area, such as continental Portugal.

\section{Methodology and Problem Solution}

The data used have been obtained from the CORINE Land Cover (CLC) project, which has its primary objective to create a multitemporal database of numerical and geographical type at 1:100.000 scale on the Coverage and Use of the Territory (Land Occupation) at the European level and National Institute of Statistics of Portugal for population 2011 censuses.

The use of a Geographic Information System (GIS) allowed different data to be measured in each of the 28 NUTS3 (nomenclature of territorial units for statistics) territorial statistical units in Mainland Portugal, known as statistical subregions (Figure 1).

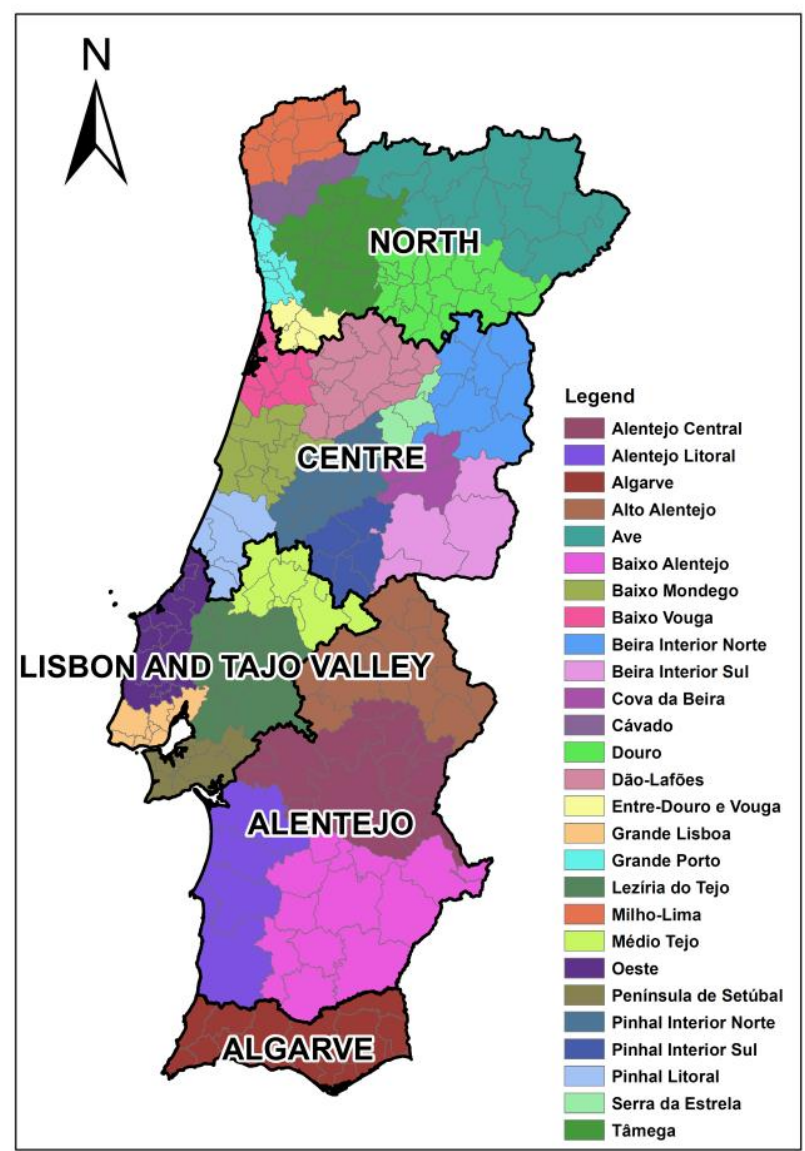

Figure 1: Map with the statistical regions and subregions of Mainland Portugal

Subregions can be differentiated on the map depicted below by different colours, as shown in the legend. These subregions are also included in other regions that are delimited by a black perimeter line and displayed their corresponding name in black text.

Firstly, the geometry was calculated for every polygon which represents a land use according to CLC. Thus it was possible to measure the are for everyone.

Secondly, the polygons which represent urban land uses were selected.

Finally, the area of these polygons was measured. So, it was possible to measure the urban areas in the analyzed years.

The data obtained were as follows:

\begin{tabular}{|l|l|c|c|c|}
\hline \multicolumn{1}{|c|}{ SUB REGION } & REGION & Pob2011 & SUP90 & SUP18 \\
\hline PT111 Minho-Lima & North & 244846 & 4016,40155 & 8324,272 \\
\hline PT112 Cávado & North & 410169 & 5151,98764 & 10575,5129 \\
\hline PT113 Ave & North & 425411 & 6696,09629 & 12959,3004 \\
\hline
\end{tabular}




\begin{tabular}{|c|c|c|c|c|}
\hline PT114 Grande Porto & North & 2649000 & 12652,5315 & 19825,4954 \\
\hline PT115 Támega & North & 551301 & 3451,21516 & 11358,3787 \\
\hline $\begin{array}{l}\text { PT116 Entre Douro e } \\
\text { Vouga }\end{array}$ & North & 276814 & 4713,71546 & 9052,55513 \\
\hline PT117 Douro & North & 205157 & 1719,89979 & 3051,04843 \\
\hline $\begin{array}{l}\text { PT118 Alto Trás-os- } \\
\text { Montesv }\end{array}$ & North & 223259 & 2533,33045 & 4501,58106 \\
\hline PT150 Algarve & Algarve & 451005 & 5300,54059 & 8801,72091 \\
\hline PT161 Baixo Vouga & Centre & 385725 & 7670,15255 & 14666,8652 \\
\hline $\begin{array}{l}\text { PT162 Baixo } \\
\text { Mondego }\end{array}$ & Centre & 340342 & 5324,12373 & 7880,57225 \\
\hline PT163 Pinhal Litoral & Centre & 249596 & 5115,39206 & 10750,0883 \\
\hline $\begin{array}{l}\text { PT164 Pinhal Interior } \\
\text { Norte }\end{array}$ & Centre & 138543 & 1043,33942 & 2510,48304 \\
\hline PT165 Dão-Lafões & Centre & 267633 & 3005,51754 & 6825,89785 \\
\hline $\begin{array}{l}\text { PT166 Pinhal Interior } \\
\text { Sul }\end{array}$ & Centre & 44804 & 350,034733 & 869,947981 \\
\hline $\begin{array}{l}\text { PT167 Serra da } \\
\text { Estrela }\end{array}$ & Centre & 49896 & 279,650794 & 540,852031 \\
\hline $\begin{array}{l}\text { PT168 Beira Interior } \\
\text { Norte }\end{array}$ & Centre & 115326 & 1574,61182 & 2537,91061 \\
\hline $\begin{array}{l}\text { PT169 Beira Interior } \\
\text { Sul }\end{array}$ & Centre & 78127 & 1255,33029 & 1954,64623 \\
\hline PT16A Cova da Beira & Centre & 93580 & 745,024905 & 1266,70356 \\
\hline PT16B Oeste & Centre & 362540 & 8145,57454 & 14830,0467 \\
\hline PT16C Medio Tejo & Centre & 247331 & 4072,82975 & 6622,85932 \\
\hline PT171 Gran Lisboa & Lisbon & 1997136 & 15346,4709 & 19388,0889 \\
\hline $\begin{array}{l}\text { PT172 Península de } \\
\text { Setúbal }\end{array}$ & Lisbon & 714589 & 8580,42318 & 12984,3392 \\
\hline $\begin{array}{l}\text { PT181 Alentejo } \\
\text { Litoral }\end{array}$ & Alentejo & 97925 & 926,659299 & 2305,87524 \\
\hline PT182 Alto Alentejo & Alentejo & 118506 & 2112,03408 & 1870,13793 \\
\hline $\begin{array}{l}\text { PT183 Alentejo } \\
\text { Central }\end{array}$ & Alentejo & 166726 & 2512,58732 & 2878,10377 \\
\hline PT184 Baixo Alentejo & Alentejo & 126692 & 2828,07914 & 2442,58766 \\
\hline PT185 Leziria do Tejo & Alentejo & 247453 & 4631,66452 & 5546,76541 \\
\hline
\end{tabular}

Table 1: Used data set.

the variables contained in the data (Table 1) are as follows:

1. SUBREGION: a qualitative variable that refers to each of Portugal Continental's subregions' name.
2. REGION: qualitative variable containing each of the regions where the different subregions are included.

3. Pob2011: population living in each subregion in 2011 obtained from National Institute of Statistics of Portugal.

4. SUP90: urban area measured in hectares in each subregion in 1990 obtained from CLC.

5. SUP18: urban area measured in hectares in each subregion in 2018 obtained from CLC.

The number of individuals is 28 , corresponding to the number of statistical subregions existing in Mainland Portugal.

A GIS was used to obtain and record each of the variables' values to obtain the above variables.

\subsection{Exploratory analysis}

Initially, an exploratory analysis of the data was started using the $\mathrm{R}$ statistical software. For this reason, the dataset summaries were obtained first. The following is the summary obtained (Table 2):

\begin{tabular}{|c|c|c|c|}
\cline { 2 - 4 } \multicolumn{1}{c|}{} & Pob2011 & SUP18 & SUP90 \\
\hline mean & $402.836,857$ & $7.397,237$ & $4.348,401$ \\
\hline sd & $571.852,00$ & $5.606,57$ & $3.606,56$ \\
\hline IQR & 267190,5 & 8408,652 & 3622,859 \\
\hline cv & 1,4195623 & 0,75792278 & 0,829399 \\
\hline skewness & 3,2214657 & 0,6956281 & 1,4730584 \\
\hline kurtosis & 10,488522 & 540,852 & 280 \\
\hline $0 \%$ & $44.804,00$ & 540,852 & 279,6508 \\
\hline $25 \%$ & $124.645,50$ & $2.493,51$ & $1.683,58$ \\
\hline $50 \%$ & $247.392,00$ & $6.724,38$ & $3.733,81$ \\
\hline $75 \%$ & 391836 & 10902,161 & 5306,436 \\
\hline $100 \%$ & 2649000 & 19825,5 & 15346,47 \\
\hline
\end{tabular}

Table 2: Mean, standard deviation, interquartile coefficient, coefficient of variation, crushing,

Kurtosis coefficient, first, second, third and fourth quartile.

Concerning Table 2 obtained, to the average obtained, as presumably, the population is the one that yields the most average. However, there is a considerable increase in comparative terms between the urban area in 2018 and 1990. It was indicated that there had been an enormous evolution in the occupation of land for urban use.

In the case of the variable referring to the population, the Kurtosis coefficient is 10.488522 , 
the data show less flattening than the Gaussian bell (leptokurtic), in the case of the variable referring to the urban area in 2018, it is equal to -0.400432 is close to zero it is mesocúrtic although slightly platicúrtic. In the case of the urban surface in 1990, it is equal to $2,454,486$. The data appear more flattened than the Gaussian bell (platicúrtic).

If we compare the coefficient of variation - i.e., the dispersion of the data about its order of magnitude, the variation of the data for the population-related variable's case is more significant. Nevertheless, if we compare the referred values for the urban area in 2018 , the variation coefficient was lower, indicating that the data's dispersion is less noticeable. Therefore, the variation of the urban area is less in 2018 than in 1990.

For urban surface variables in 1990 and 2018 histograms were obtained (Figures 2 and 3).

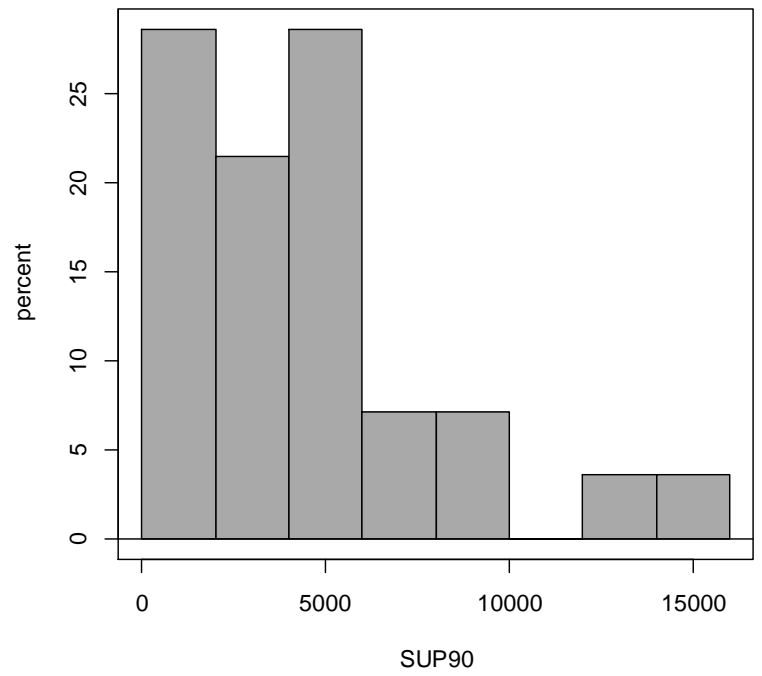

Figure 2: Urban surface histogram in 1990

In this histogram (Figure 2), the peaks would be included for the first and third bars - i.e., the most repeated values would be close to 0 and 5000 hectares of surface area. Also, there is a bar with insufficient data in the sample to be displayed in the histogram, that bar corresponding to the values that are immediately greater than 10000 . In this regard, the sample size is 28 , if it were larger, possibly if values had been recorded that had been represented in the last bar mentioned. Besides, it is observed that the data are asymmetrical. As a result, they may not be distributed normally.

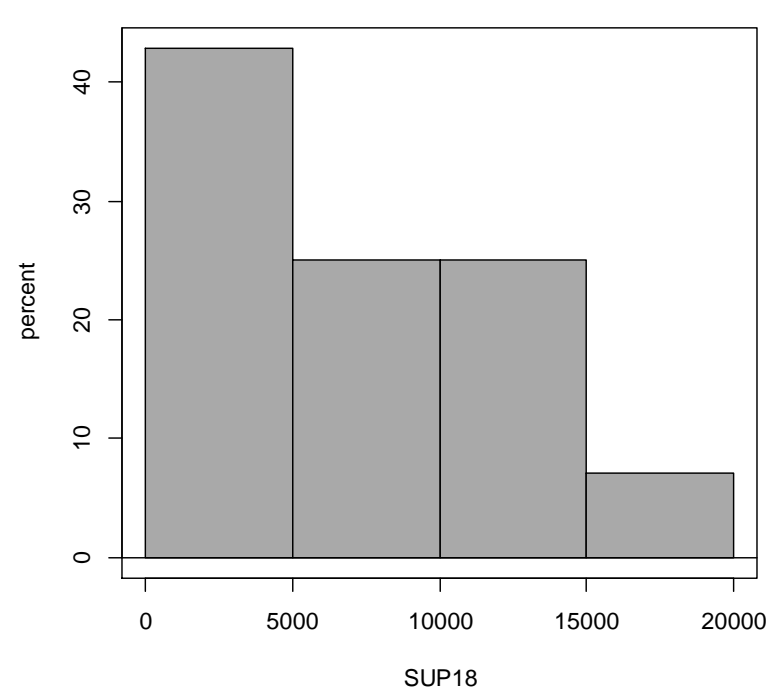

Figure 3: Urban surface histogram in 2018

The above histogram (Figure 3) shows that the peak is in the first bar. Therefore, the values repeated the most, in terms of urban areas in 2018, are also close to 0 and less than 5000. In this case, all bars are represented even though we have a sample of only 28 individuals. Also, it is observed that the data are asymmetrical. As a result, they may not be distributed normally.

If we compare both histograms, we can say that the urban area in each municipality has consolidated over the years in smaller areas, being usually less than 5000 hectares. Therefore, we can say that urban land has been disseminated or divided over the years.

Precisely, to see if this general trend throughout Portugal Mainland occurs in each of the regions studied. Thus, the histograms for the variable related to the urban area in 1990 and 2018 are obtained for each region to evaluate and compare the groups' center and dispersion. 

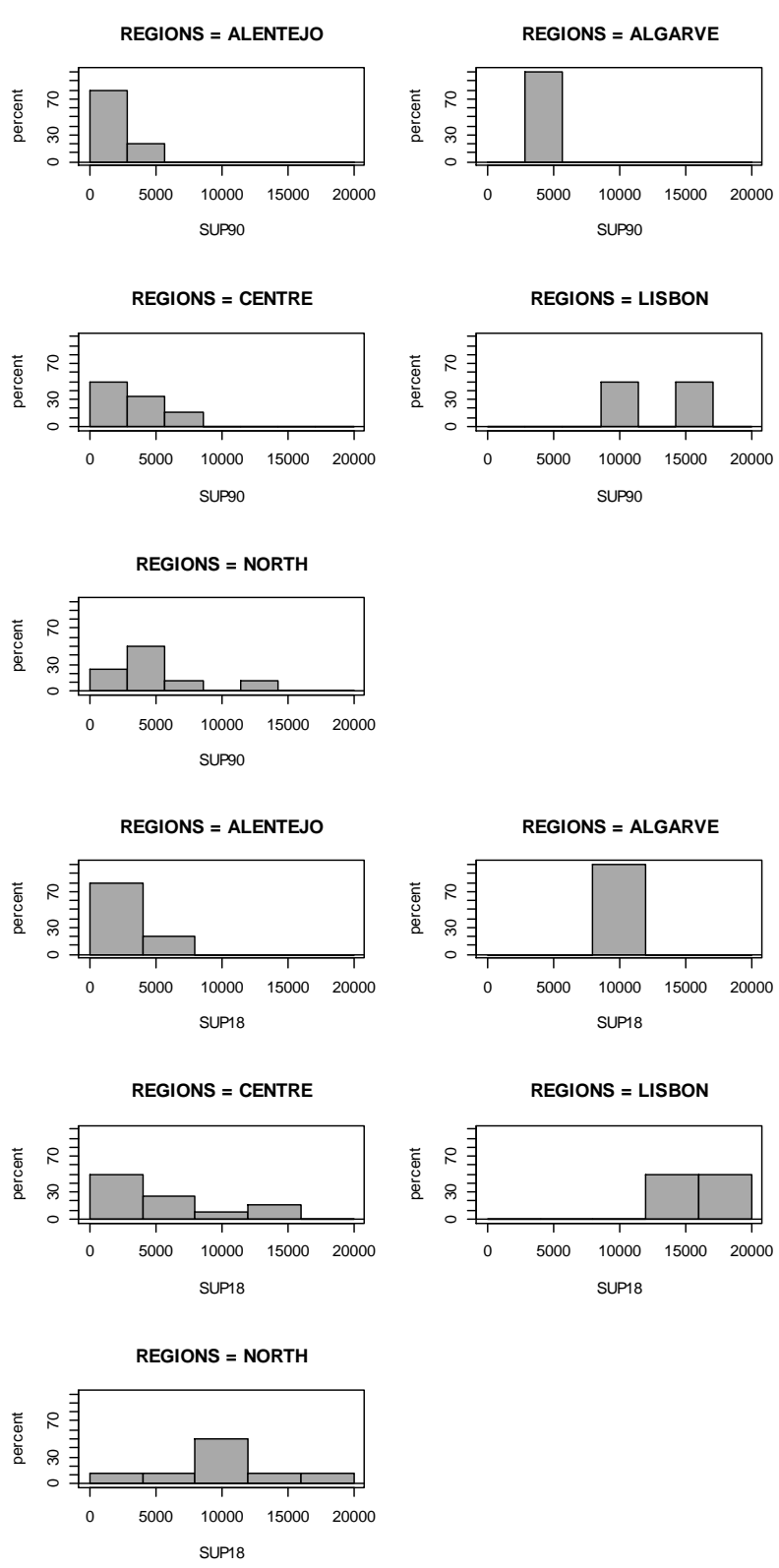

Figure 4: Histograms for urban areas in 1990 and 2018 in each region

According to Figure 4, in the North region, an asymmetrical diagram was observed in 1990, contrasting with the symmetrical diagram in 2018, with the peak right in the middle, as the most common values are close to 10000 . Therefore, in this region, it has gone from values of less than 10000 hectares to being the most common 10000 hectares, showing that there has been an effect contrary to that of dissemination, there is a grouping of urban land.

A similar scenario occurs in the Algarve Region. However, there are only values close to 10000 since there is only one subregion. Therefore, as in the other regions, there are also unrepresentative values represented by a bar in the histogram. For this reason, it would be advisable to increase the number of samples. In fact, in 2018, there is also dysmetria for the Centro, Lisbon, and Alentejo region.

Also, let us compare the peaks of each of the regions. Although it is centered in the North region and Algarve in the Central and Alentejo regions, the urban areas are most frequently found in values close to 0 and the Lisbon region contrary to values closer to 15000 and 20000. Therefore, we can say that the Centro and Alentejo regions could dominate scattered regions, and in the Lisbon region, a more intense urban concentration could prevail.

The bar chart for the urban surface variable was also obtained in 1990 for each of the 28 subregions (Figure 5).

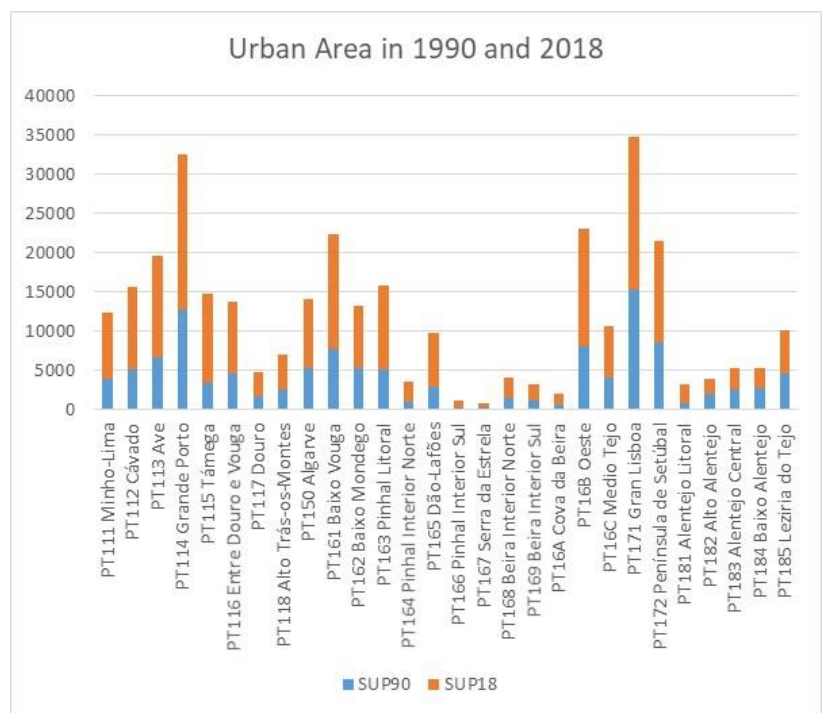

Figure 5: Urban area in 1990 and 2018 for each region

Figure 5 shows the total urban area obtained in each of the 28 subregions, highlighting the bar for the Greater Lisbon subregion, where the largest urban area was hosted in 1990.

Moreover, the variable related to the urban area in 2018 in this bar chart can be observed as general terms have increased the urban area. Although the subregion of Gran Lisboa remains one of the largest cozy urban areas, it has been surpassed by the region of Grande Porto. Therefore, we could say that the Grande Porto region has been the subregion where the highest urban growth occurred between 1990 and 2018.

\subsubsection{Data distribution}

Subsequently, density plots were obtained for the occupied urban area in each subregion in 1990 and 2018 (Figures 6 and 7). 


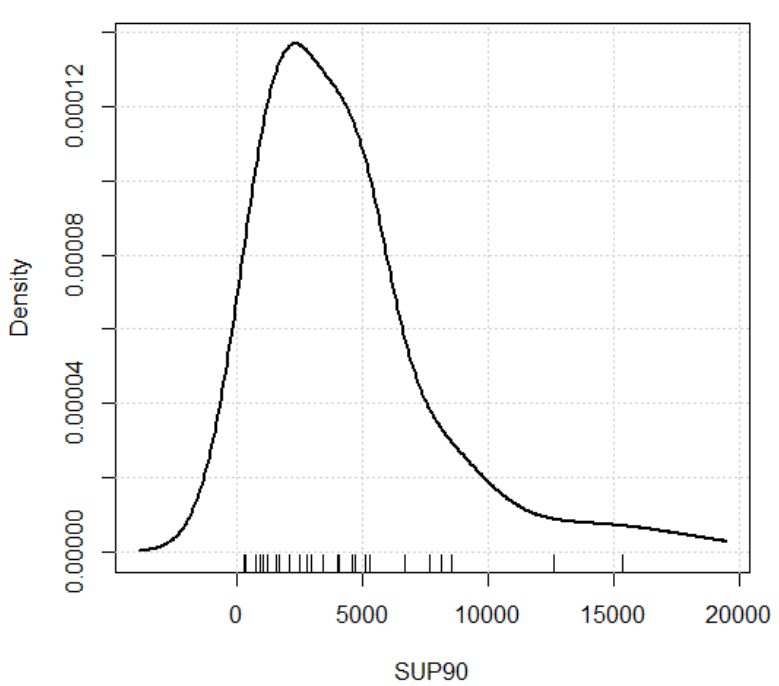

Figure 6: Density graph for the urban area in 1990

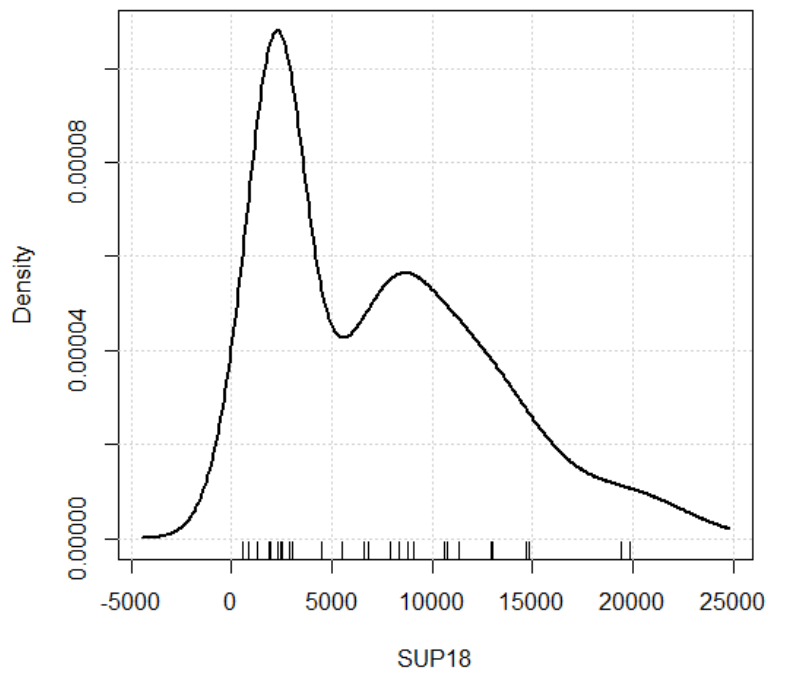

Figure 7: Density graph for the urban area in 2018

Thus we get the density estimate. These curves (Figures 6 and 7) help us to better describe the data distribution. The two distributions obtained are asymmetrical, as they are shifted to the left. In this way, we again confirm that there are more multiple values whose urban area is less than 5000 hectares in the municipalities.

Furthermore, if we compare both graphs, we can see that in 1990 the density of values gradually decreases as the urban area increases. However, in 2018 there is a sharp decline before reaching 5000 hectares of urban land, then rises slightly and again gradually decreases. Therefore, although there is an exact threshold of 5000 hectares in 1990, in 2018, this threshold appears to be set at a value of 5000 hectares.

Once again, we can clearly say that the spread of soil in 2018 has been much more intense than in 1990. We can also see that the urban area in 2018 has a more significant crash, indicating a greater concentration of values. Contextually, we obtained the box diagrams for the same variables (Figures 8 to

11):

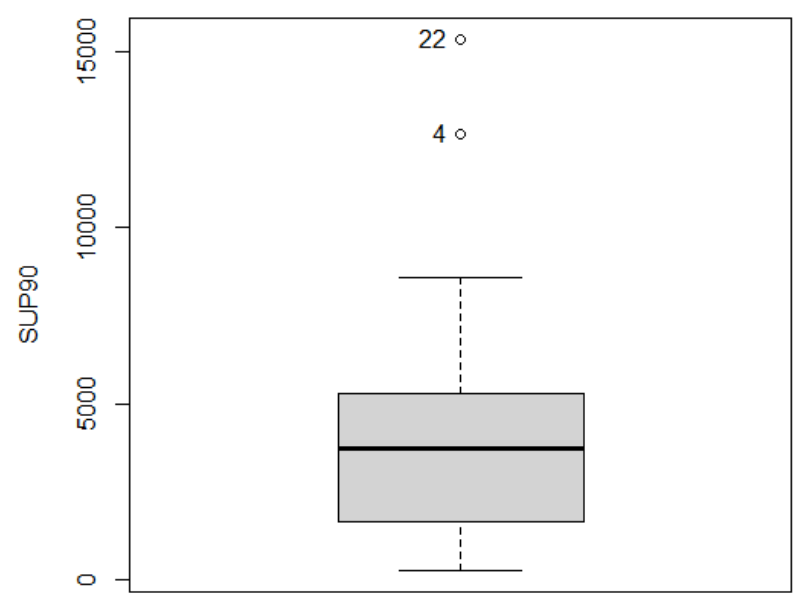

Figure 8: Box diagram for the occupied urban area in 1990

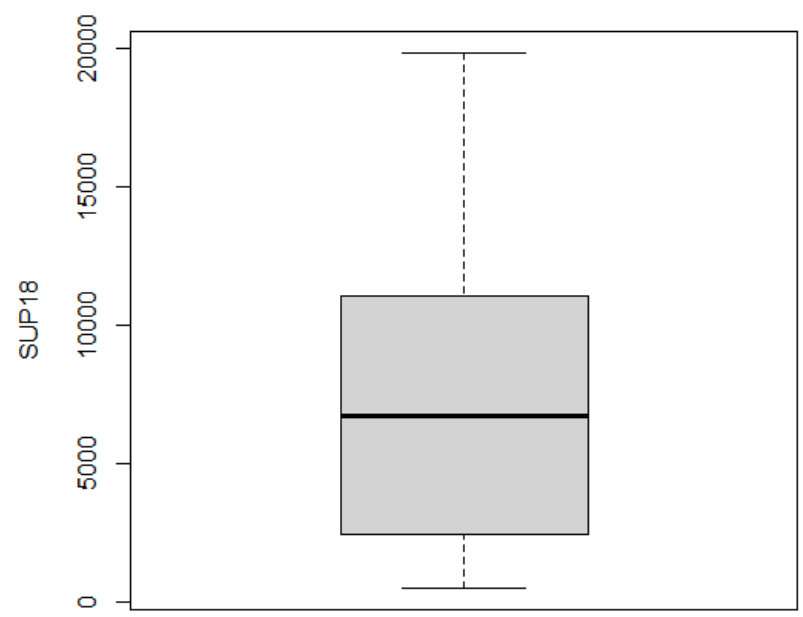

Figure 9: Box diagram for the occupied urban area in 2018

We can see that in the case of the urban area in 1990 (Figure 8), there are two outliers, and the average is between 0 and 5000 hectares. Still, in 2018 (Figure 9), the average is above 5000 hectares, and outliers disappear.

However, for more descriptive information, box diagrams are made for each of the regions in both 1990 and 2018. 


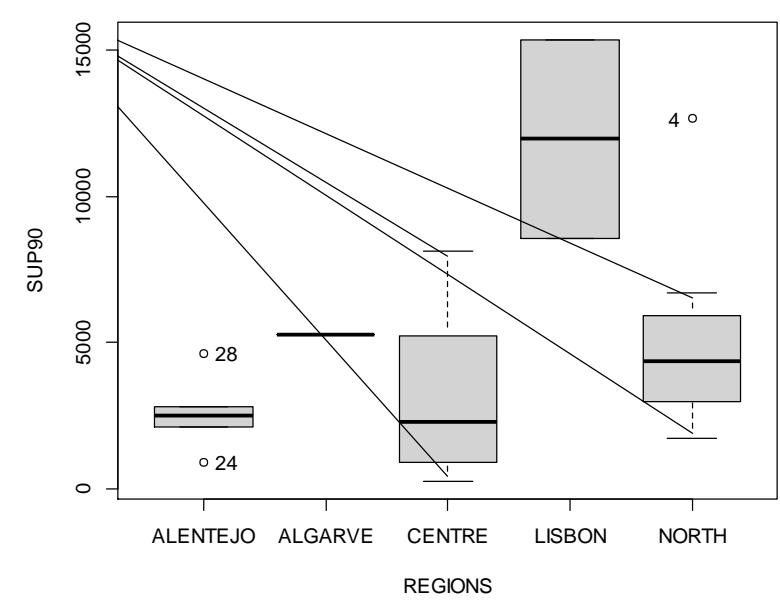

Figure 10: Box diagrams for the urban area occupied in 1990 in the Alentejo, Algarve, Centre, Lisbon and North regions.

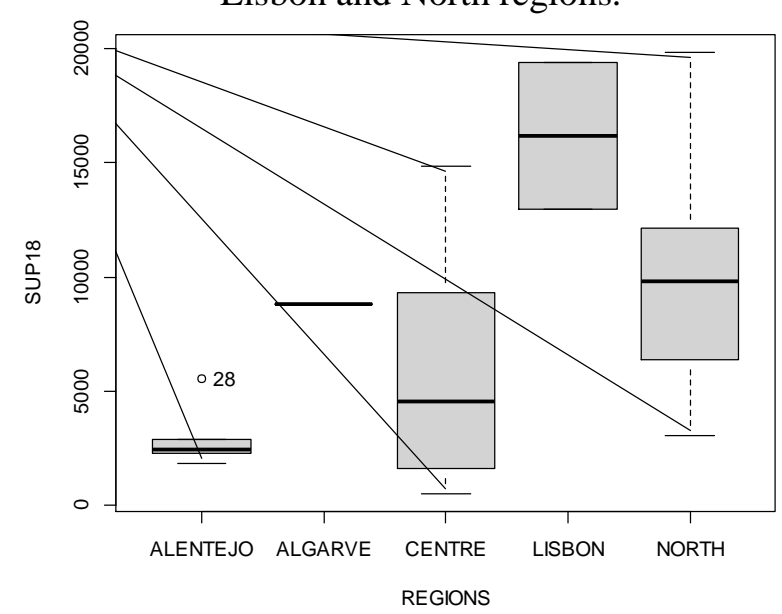

Figure 11: Box diagrams for the urban area occupied in 2018 in the Alentejo, Algarve, Centre, Lisbon and North regions.

Comparing the box diagrams (Figures 10 and 11) for the North region disappears the outlier, and the interquartile range increases considerably. Therefore, the dispersion of urban area values increases in 2018. Also, the median value increases and is closer to the third quartile. Therefore, the average value in the dataset is closer to larger values.

Regarding the Algarve region, because only one individual notices an increase in the value of the individual. As for the Central region, a higher interquartile range again appears, and the median increases, in this case, closer to the value of the first quartile. However, for the Lisbon region, the inter quarterly range decreases, although the median increases while maintaining a central position within the inter quarterly range. As for the Alentejo region, one of the outliers disappears, the interquartile range is reduced, placing the median in a position closer to the first quartile.
The quantile comparison graphs for the urban area in 1990 and 2018 were also obtained (Figures 12 to 14).

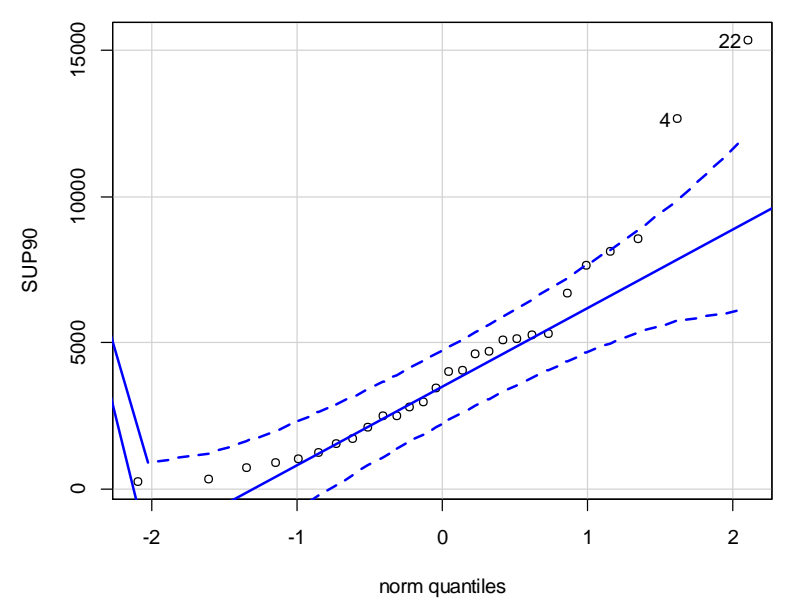

Figure 12: Quantile comparison plot for the urban area in 1990

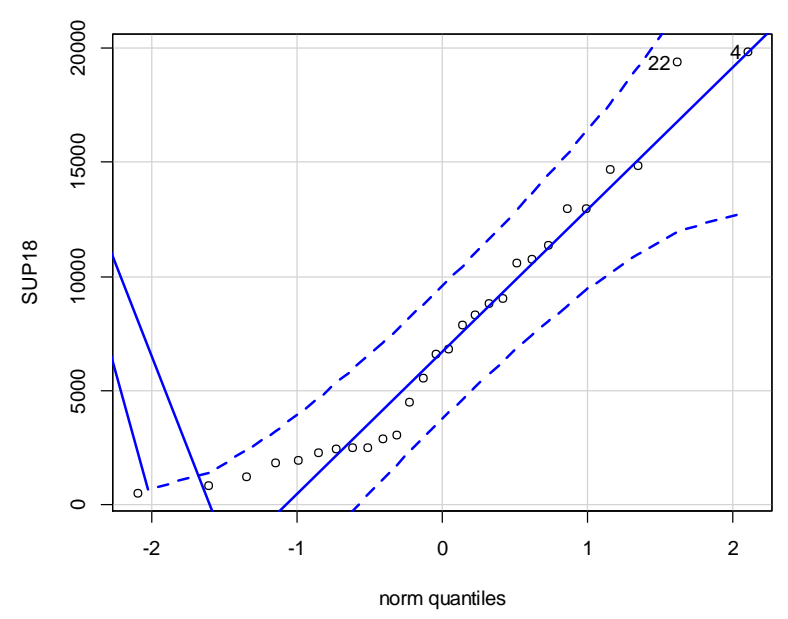

Figure 13: Quantile comparison graph for the urban area in 2018

The above graphs show how close the data set's distribution refers to hectares of urban land use to an ideal distribution. If we compare both years, we can see that the data follows a normal distribution. Also, comparing both graphs, we see that the ideal distribution slope is much higher in the case of 2018. Therefore, we can interpret that the frequency of values will be higher as urban land increases. In addition, such graphs were obtained for each region in both years. 

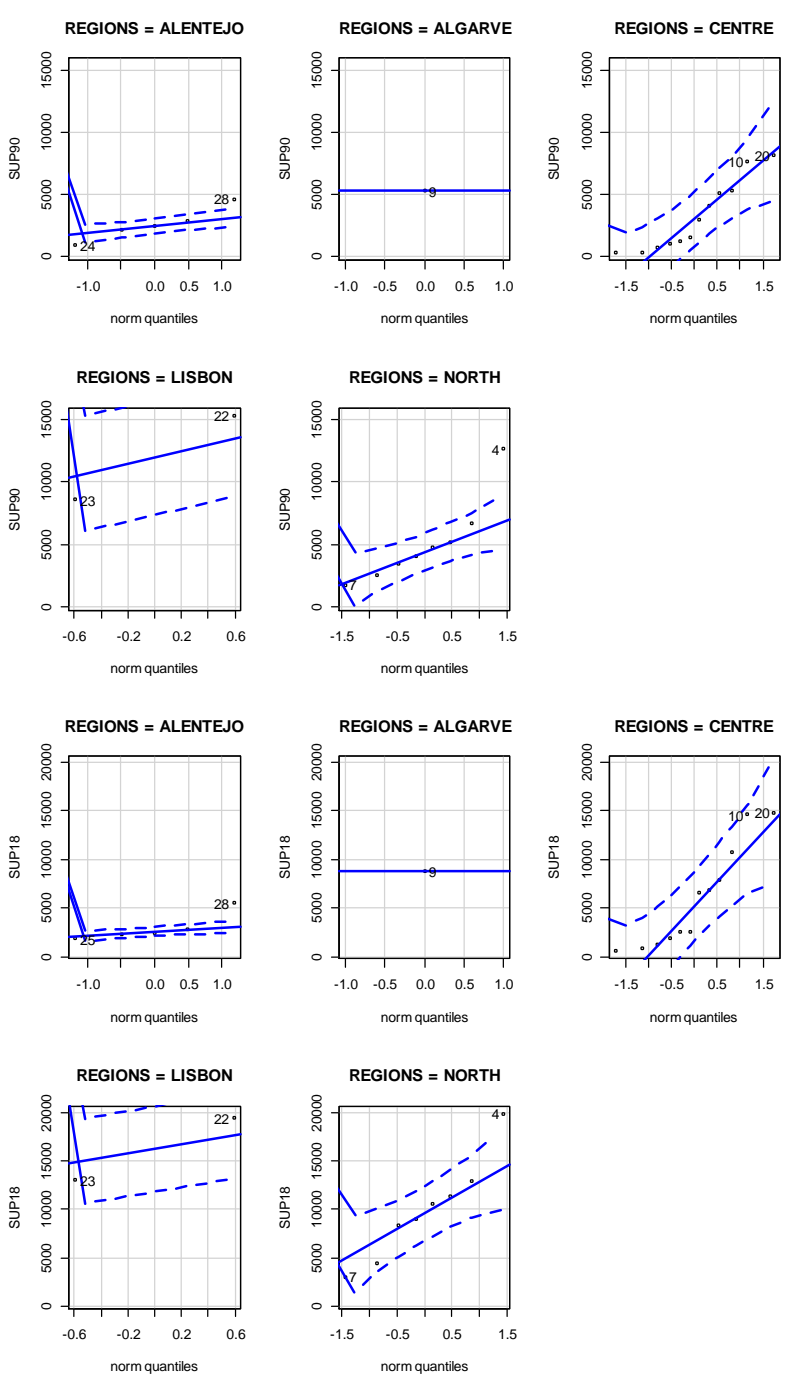

Figure 14: quantum comparison chart for the urban area in 1990 and 2018 in each region

The graphs of Figure 14 allow us to observe that more values are required except for the Center and North regions. In both cases, there is a higher slope in 2018, indicating a higher frequency of values as the extent of the urban area increases. The observations come from variables with the same characteristics and the variables are continuous. Therefore, the trajectory of the points determined by the pairs of quantiles tends to be more similar to the straight line of the identity function for the case of the North Region, with more statistical discrepancies between the two data sets for the Central Region both in 1990 as in 2018. Graphs are also used to determine whether a set of observations comes from a variable with a given theoretical probability model. In this case, the observations are compared with the quantiles of the theoretical model. In the case of the Northern Region, it would come in a more adjusted way to this theoretical model.
Once the exploratory analysis of the data was carried out, the relationship between the population in 2011 and the urban area in 2018 - i.e., the relationship between two quantitative variables, was observed.

Initially, a scatter plot was made to see the relationship between the quantitative population variable in 2011 and an urban area in 2018. Contextually, we have drawn a straight line that represents the least-squares line as far as all the possible points (Figures 15 and 16).

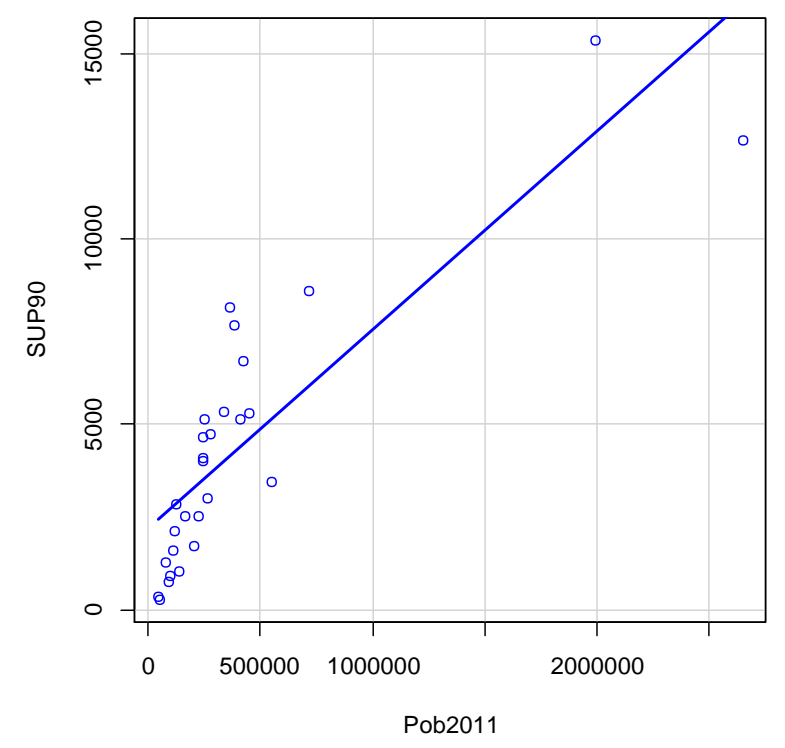

Figure 15: Scatter chart between the population in 2011 and the urban area occupied in 1990

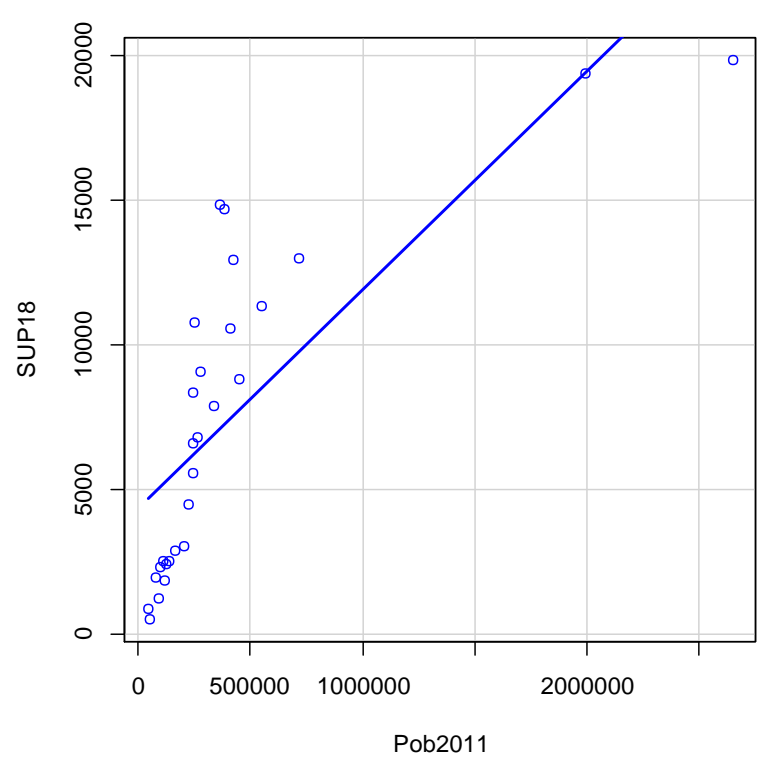

Figure 16: Scatter chart between the population in 2011 and occupied urban area in 2018

In this case, when the values of the population variable increase (Figure 15 and 16), the urban surface variable's values also increase in 1990 and 
2018. Hence, there is a direct or positive relationship between the two variables.

\subsection{Correlation analysis}

We have also calculated the graph of the scatter plot matrix for the resident population in 2011, but the urban area in both 2018 and 1990.

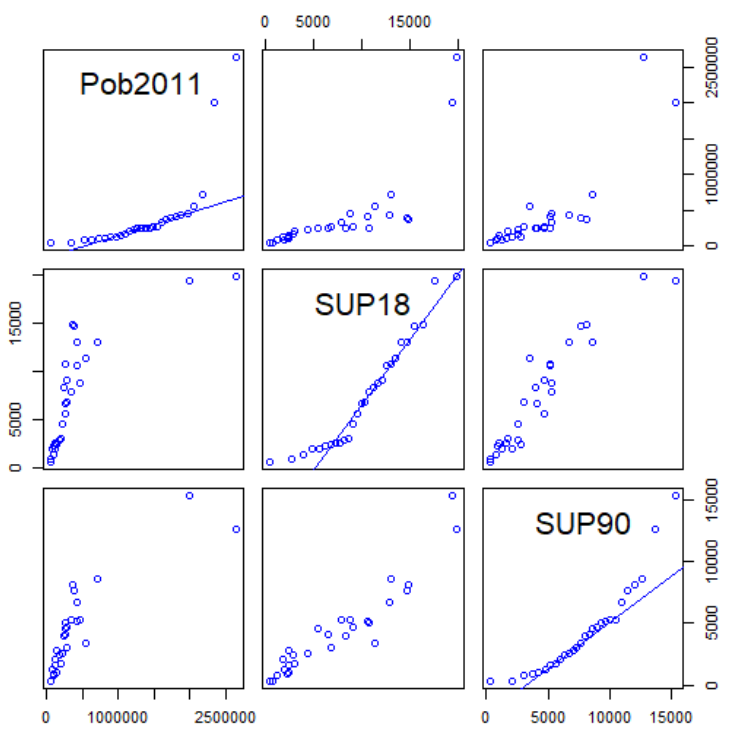

Figure 17: Matrix of scatter plots for population variables in 2011 and occupied urban area in 1990 and 2018.

In all cases (Figure 17), there is a direct relationship between the variables considered. Subsequently, we have determined the correlation matrix using Pearson's correlation coefficient (Table 3).

\begin{tabular}{|l|l|l|l|}
\hline & Pob2011 & SUP18 & SUP90 \\
\hline Pob2011 & 1 & 0.7715374 & 0.849619 \\
\hline SUP18 & 0.7715374 & 1 & 0.9398840 \\
\hline SUP90 & 0.8496196 & 0.9398840 & 1 \\
\hline
\end{tabular}

Table 3: Pearson correlation matrix for population variables in 2011 and urban area in 1990 and 2018.

The results enable us to identify a direct linear relationship of medium-high degree between the population and urban area variables in 2018 and 1990, even more, significant correlation with the urban area in 1990. There is also a high correlation between the urban area in 2018 and 1990. It is the maximum correlation between the analyzed variables. The obtained value (Table 3) 0.7715374 is greater than 0 , with direct linear correlation being. Therefore, we can talk about a direct linear relationship of medium-high degree between the population in 2011 and the urban area in 2018.

\subsubsection{Statistical inference}

Eventually, the statistical inference was made by comparing two dependent or mated populations using the following approach. It is desired to recognize whether the Portuguese Government measures have significantly increased the urban area in Portugal Mainland. The urban area (in hectares) was measured in each of the 28 NUTS3 territorial statistical units in mainland Portugal in 1990. It was then re-quantified in 2018 using Corine Land Cover. It is set for the 5\% significance level if the Portuguese government's actions have produced differences in the urban land generation.

Therefore, initially, a new variable determined by the difference between urban land was calculated before (1990) and after (2018). Then the normality of the values received in the new calculated variable is checked by applying the Shapiro-Wilk test since the number of individuals is 28 , being $\mathrm{n}<30$. Obtaining the following values:

$\mathrm{W}=0.92514, \mathrm{p}$-value $=0.04655$

In this regard, taking into account the p-value value, normality is discarded, and a non-parametric test is performed. In this case, the Wilcoxon test for paired samples. The first variable selects the urban area measured in hectares in 1990 for each of the 28 regions, and as a second variable, the urban area was selected in 2018 .

$\mathrm{V}=5, \mathrm{p}$-value $=0.00000007451$

Based on the $p$-value value, it can be said that there are significant differences between the urban area measured in mainland Portugal in the NUTS3 regions between 1990 and 2018, following the measures taken by the Portuguese Government.

\section{Conclusion}

According to the results, we can say that the population and the urban area in Portugal Continental have increased in the analyzed period of 1990-2018. Also, highlight the direct correlation that exists between the growth of the urban area and the increase in population.

It should be noted that Greater Porto has surpassed Greater Lisbon as the largest urban area. Therefore, we could say that the Grande Porto region has been the subregion where the highest urban growth occurred between 1990 and 2018 . 
Regarding the population distribution, the results show that the Central regions and the Alentejo regions predominate a dispersed population distribution, and in the Lisbon region, a more intense urban concentration prevails.

In conclusion, the present study reveals the changes produced in the urban areas of continental Portugal in the last years of the 20th century and the beginning of the $21 \mathrm{st}$. The new scenario of globalization, increasingly developed, has caused that traditional planning based on physical and spatial planning of cities is not enough for the promotion of public policies for urban development. Therefore, understanding urban dynamics will provide territory managers with a useful tool to establish an urban development consistent with the population and economic growth of each population nucleus, integrated into a population, regional, district and national system.

In this regards, a clear tendency was identified according to the density of population and measured area of the urban area. Indeed, a historical region such as Lisbon was overcome by Grande Porto. So it would advisable to observe if this tendency in the future is going to be higher. In this case, Grande Porto could be more important than Lisbon concerning the socio-economic system in Portugal. Indeed, if the socio-economic system was taken into account, it could determine a possible correlation between the different areas analyzed.

\section{References:}

[1] Fadigas, L. (2015). Urbanismo $e$ Território-As Políticas Públicas; Edições Sílabo: Lisbon, Portugal.

[2] Naranjo Gómez, J.M., Loures, L., Castanho, R.A., Cabezas, J., Fernández-Pozo, L., Lousada, S., Escórcio, P. (2018). Assessing Land Use Changes in European Territories: A Retrospective Study from 1990 to 2012. IntechOpen, DOI: 10.5772/intechopen.80827.

[3] Gao, P., Niu, X., Wang, B. and Zheng, Y. (2015). Land use changes and its driving forces in hilly ecological restoration area based on gis and rs of northern China. Scientific Reports 5, Article number: 11038 (2015).
[4] Loures, L., Panagopoulos, T., and Burley, J. (2016). Assessing user preferences on postindustrial redevelopment. Environ. Plan. B Plan. Des. 2016, 43, 871-892.

[5] Naranjo Gómez, J.M., Lousada, S., Garrido Velarde, J., Castanho, R.A., and Loures, L. (2020). Land Use Changes in the Canary Archipelago Using the CORINE Data: A Retrospective Analysis. Land 2020, 9, 232; doi:10.3390/land9070232

[6] Castanho, R. (2017). Sustainable Urban Planning in transboundary areas: analysis of critical factors for territorial success. Ph.D. Thesis (Badajoz: University of Extremadura (UEx).

[7] Loures, L., Castanho, R.A., Vulevic, A., Naranjo Gómez, J., Cabezas, J., and FernándezPozo, L. (2018). The Multi-variated Effect of City Cooperation in Land Use Planning and Decision-making Processes-A European Analysis. In Urban Agglomerations; InTech: Vienna, Austria, 2018; pp. 87-106, ISBN 978953-51-5884-4.

[8] Codosero Rodas, J., Castanho, R.A., Cabezas, J., and Naranjo Gómez, J. (2020). Sustainable valuation of land for development. Adding value with urban planning progress. A Spanish case study. Land Use Policy 92 (2020) 104456

https://doi.org/10.1016/j.landusepol.2019.10445 6

[9] Loures L, and Panagopoulos T. (2010). Reclamation of derelict industrial land in Portugal - greening is not enough. International Journal of Sustainable Development and Planning. 2010;5(4):343-350

[10] Castanho, R.A. (2019). Identifying Processes of Smart Planning, Governance and Management in European Border Cities. 
Learning from City-to-City Cooperation (C2C). Sustainability 2019, 11, 5476; doi:10.3390/su11195476.

[11] Codosero Rodas, J., Naranjo Gómez, J., Castanho, R.A., and Cabezas, J. (2018). Land Valuation Sustainable Model on Urban Planning Development: A Case Study in Badajoz, Spain. Sustainability 2018, 10, 1450; Special Issue Smart Cities and Villages. doi:10.3390/su10051450.

[12] Pinto-Correia. T, Kristensen. L. (2013) Linking research to practice: The landscape as the basis for integrating social and ecological perspectives of the rural. Landscape and Urban Planning. $\quad 2013 ; 120: 248-256$ DOI: 10.1016/j.landurbplan.2013.07.005

[13] Santana-Cordero, A. M., MonteiroQuintana, M. L., and Hernández-Calvento, L. (2016). Re-construction of the land uses that led to the termination of an arid coastal dune system: the case of the Guanarteme dune system (Canary Islands, Spain), 1834-2012. Land Use Policy, 55, 73-85.

\section{Sources of funding for research presented in a scientific article or scientific article itself}

The publication of the present work was possible thanks to funding granted by the European Regional Development Fund (FEDER in Spanish) and by the Board of Extremadura to the Research Group of Sustainable Development and Territorial Planning through the financial help of reference GR18052.

\section{Creative Commons Attribution License 4.0 (Attribution 4.0 International , CC BY 4.0)}

This article is published under the terms of the Creative Commons Attribution License 4.0 https://creativecommons.org/licenses/by/4.0/deed.en US 